Fifth International Conference on Sustainable Construction Materials and

Technologies. http://www.claisse.info/Proceedings.htm

\title{
QUALITY CONTROL METHODOLOGY FOR COMPOSITE FRP REBARS
}

\author{
Leire Echeverria ${ }^{1}$, Alvaro Ruiz Emparanza ${ }^{2}$, Antonio Nanni $^{3}$, Francisco De Caso y \\ Basalo $^{4}$
}

${ }^{1} 1251$ Memorial Dr, Coral Gables, FL 33146; 1xe202@ miami.edu; University of Miami, Department of Civil, Architectural, and Environmental Engineering

${ }^{2} 1251$ Memorial Dr, Coral Gables, FL 33146; axr1489@ miami.edu; University of Miami, Department of Civil, Architectural, and Environmental Engineering

${ }^{3} 1251$ Memorial Dr, Coral Gables, FL 33146; nanni@ miami.edu; University of Miami, Department of Civil, Architectural, and Environmental Engineering

${ }^{4} 1251$ Memorial Dr, Coral Gables, FL 33146; fdecaso@ miami.edu; University of Miami, Department of Civil, Architectural, and Environmental Engineering

\begin{abstract}
The increasing demand on reinforced concrete infrastructure, coupled with environmental challenges, results in accelerated degradation evident for example by corrosion. Composite FRP rebar used to reinforce concrete structures can address durability challenges, making progress towards a safe and resilient built infrastructure. While FRP rebars have been commercially available for at least two decades, with the foreseen increasing demand for its use, establishing reliable and effective quality control (QC) methodology to provide assurance of the manufactured composite rebar properties is paramount for full implementation of this concrete reinforcing technology; and assure extended service life, safety and reliability of concrete infrastructure.

This study first presents an initial QC assessment criterion, which is applied to existing QC standard specification, and then validates an alternative methodology based on a flexural test of FRP rebars as a response to the need of additional reliable, effective and rapid tests that FRP rebar manufactures can implement to assess the continued quality of pultruded rebars during production. To this end, various parameters where preliminary evaluated including, two test configurations, span-to-depth ratios, eight manufactures and three different rebar diameters per manufacture (nominal $9.5 \mathrm{~mm}$, $12.7 \mathrm{~mm}, 25.4 \mathrm{~mm})$.
\end{abstract}

Overall the selected test procedure was validated with over 100 tests and results compared and correlated to FRP rebar tensile properties. Based on the results, reliable and valid physio-mechanical properties can be determined from the test protocol, which can be directly related to design properties. The test is time- and cost- effective and can be adopted to obtain quantitative quality control data in as little as seven minutes. 


\section{INTRODUCTION}

The development of composite materials, such as FRP composites, are widely used in existing and new construction applications. They combine a reinforcing phase (fibers) and a matrix (polymer). Such multifunctional materials represent an important advance in construction technologies, offering many innovative properties which are not possible with conventional materials such as those found in ferrous and non-ferrous metals. It is well established that FRP is non-corrosive, light weight, higher strength and provides longer service life to reinforced concrete structures (Nanni et al., 2014).

For more than two decades composite FRP reinforcement for concrete has been commercially available, nevertheless there are no well-established and mature quality control (QC) methodologies for manufactured FRP rebar. The need to guarantee desired quality standards as it relates to construction materials is a necessary step to assure FRP rebar functionality, infrastructure design and avoid potential failures. Therefore, QC protocols to define mechanical properties of rebars for the manufactured rebar is needed, to assure reliability and that a desired level of quality has been obtained from the manufactured product.

Standard guidelines for quality control and certification of glass FRP rebars have shown limitations to detect defects during production (Trejo et al. 2005). Recently, a standard specification ASTM D7957 applicable to GFRP rebars (FRP composites with glass fibers) specifies a set of mechanical tests for QC purposes, however such QC methodology has shortcomings related to the time needed to obtain meaningful results, which varies from the different tests and overall may take between 3 to 7 days to complete the specified QC needs, where only one test is used to confirm design properties. This test is time consuming due to the specimen preparation procedure; one anchor at each end of the specimen need to be installed for the gripping system. As such the QC method may yield low reliability and response time impacting manufacturers and construction, if the rebar has been delivered and placed on site. These shortcomings are recognised by manufacturers, where a quick and reliable method that provides quantitative data would add value to improve the QC of FRP rebars.

To this end, this study proposes an initial QC assessment criterion and develops and validates a reliable, effective and rapid methodology based on a flexural test protocol to increase the reliability and response time of QC of manufactured FRP rebar. This QC test can enable early detection of possible non-compliant manufacturing processes or defects immediately after production (Whitney and Knight, 1980). Thus, this complementary QC test can provide effective, low cost, and higher QC. Lastly, results are compared to tensile tests (per ASTM D7205) to determine correlations between flexural and tensile properties, therefore increasing further the value provided by a flexural QC test. 


\section{RESEARCH SCOPE: QC CRITERION}

Industries such as boating, aerospace and power (windmill) have extensive established quality control methodologies and processes have resulted in certification programs implemented to validate the characteristics and manufacturing of produced FRP components or systems of all shapes and sizes. This manufacturing certification is necessary to assure safety, increasing the reliability of product and assesses key material or component characteristics based on standard testing procedures (Wind energy generation systems), (Corli Leonard, 2011). Moreover, such manufacturing certification programs have resulted in market growth, increased safety, and trust by stakeholders in the value chain. In order to asses if the current QC program for glass FRP bars meets desired needs, an initial QC assessment criterion is proposed. This initial suggested criterion, aims at evaluating and determining the significance of the existing QC specification as defined by Table 2 in ASTM D7957. This initial criterion is composed of five considerations regarding QC that are important from a manufacturing process and value chain view, and are described herein. A criterion value between 1 and 5 is then defined in Table 1, where 1 and 5 represent a low and high value, respectively, to the $\mathrm{QC}$ process and manufacturer.

I. Time: Time needed to yield data that provides results relevant to specifications. A significant advantage for in-line production (around $1 \mathrm{~m} / \mathrm{min}$ ) is to provide a fast test that can assure manufactured product meets mechanical properties. Saving time between evaluation and data, results in a faster reaction during production to implement corrections as needed, reducing waste and manufacturing costs.

II. Cost/Effort: Monetary, technical and human resource (in terms of training, equipment, technical skill...etc.) needed to yield data that provides results relevant to specifications. Conducting a straight forward test, where training requirements are basic, and standard equipment is utilized, as well as the time required to conduct the test by the operators, results in a cost effective and feasible test to implement in manufacturing, reducing waste and manufacturing costs.

III. Detected failure/imperfections: Ability of the test to correlate results to potential manufacturing non-compliance that can support failure analysis. The relevance of a QC test to detect imperfections - specially related to design properties - in the manufacturing process is critical in order to assure the reliability of the process and finished product.

IV. Output parameter/result: The significance of the QC test result (output parameter) as it relates to design related properties in the context of reinforced concrete structures. If the test results in parameters that are directly related to design properties, this will increase the reliability and assurance of the QC methodology, as it related to the manufactured FRP rebar.

V. Assessment/evaluation of constituent materials: The ability of the QC test to assess and evaluate each FRP rebar constituent material (i.e. the resin matrix and/or 
fibers). A QC test method that can pin point specifically the performance and of specific constituent materials, would be advantageous to identify specific supplier related or manufacturing handling problems, while also increasing the reliability of the overall FRP manufactured rebar.

Table 1. Initial criteria to assess QC Specification per ASTM D7957- Table 2

\begin{tabular}{|c|c|c|c|c|c|c|}
\hline $\begin{array}{l}\text { Criterio } \\
\text { n Value }\end{array}$ & $\begin{array}{c}\text { I } \\
\text { Time }\end{array}$ & $\underset{\text { Cost/effort }}{\text { II }}$ & $\begin{array}{c}\text { III } \\
\text { Detected } \\
\text { imperfection } \\
\text { s/ } \\
\text { failure }\end{array}$ & $\begin{array}{c}\text { IV } \\
\text { Output } \\
\text { Paramet } \\
\text { er }\end{array}$ & $\begin{array}{c}\text { Va } \\
\text { Assessm } \\
\text { ent of } \\
\text { constitu } \\
\text { ent: } \\
\text { resin }\end{array}$ & $\begin{array}{c}\text { Vb } \\
\text { Assessm } \\
\text { ent of } \\
\text { constitu } \\
\text { ent: } \\
\text { fiber }\end{array}$ \\
\hline 1 & $\begin{array}{l}\text { One } \\
\text { week }\end{array}$ & $\begin{array}{c}\text { Training } \\
\text { needed, high } \\
\text { cost, difficult } \\
\text { to handle }\end{array}$ & $\begin{array}{c}\text { Visual } \\
\text { detectable } \\
\text { imperfection } \\
\mathrm{s}\end{array}$ & $\begin{array}{c}\text { No } \\
\text { design } \\
\text { relationsh } \\
\text { ip }\end{array}$ & $\begin{array}{l}\text { Not } \\
\text { resin } \\
\text { related }\end{array}$ & $\begin{array}{c}\text { Not } \\
\text { fiber } \\
\text { related }\end{array}$ \\
\hline 2 & $120 \mathrm{hrs}$ & $\begin{array}{l}\text { Training } \\
\text { needed, } \\
\text { medium-high } \\
\text { cost, difficult } \\
\text { to handle }\end{array}$ & $\begin{array}{l}\text { Quantitative } \\
\text { future } \\
\text { defects }\end{array}$ & $\begin{array}{l}\text { Low } \\
\text { design } \\
\text { relationsh } \\
\text { ip }\end{array}$ & $\begin{array}{l}\text { Indirectl } \\
\text { y resin } \\
\text { related }\end{array}$ & $\begin{array}{c}\text { Indirectl } \\
\mathrm{y} \text { fiber } \\
\text { related }\end{array}$ \\
\hline 3 & $48 \mathrm{~h}$ & $\begin{array}{l}\text { Training } \\
\text { required, } \\
\text { medium level } \\
\text { of } \\
\text { performing, } \\
\text { medium cost }\end{array}$ & $\begin{array}{l}\text { Quantitative } \\
\text { defects }\end{array}$ & Indirect & $\begin{array}{l}\text { Resin } \\
\text { related }\end{array}$ & $\begin{array}{l}\text { Fiber } \\
\text { related }\end{array}$ \\
\hline 4 & $24 \mathrm{hrs}$ & $\begin{array}{l}\text { Little } \\
\text { training } \\
\text { required, } \\
\text { easy to } \\
\text { perform, } \\
\text { medium cost }\end{array}$ & $\begin{array}{l}\text { Qualitative } \\
\text { defects }\end{array}$ & $\begin{array}{l}\text { Quasi- } \\
\text { Direct }\end{array}$ & $\begin{array}{l}\text { Quasi- } \\
\text { directly } \\
\text { resin } \\
\text { related }\end{array}$ & $\begin{array}{l}\text { Quasi- } \\
\text { directly } \\
\text { fiber } \\
\text { related }\end{array}$ \\
\hline 5 & $\begin{array}{l}\text { less } \\
\text { than } \\
24 \mathrm{~h}\end{array}$ & $\begin{array}{l}\text { Little } \\
\text { training } \\
\text { required, } \\
\text { easy to } \\
\text { perform, low } \\
\text { cost }\end{array}$ & $\begin{array}{l}\text { Qualitative } \\
\text { and } \\
\text { quantitative } \\
\text { defects }\end{array}$ & $\begin{array}{l}\text { Directly } \\
\text { Design }\end{array}$ & $\begin{array}{l}\text { Directly } \\
\text { resin } \\
\text { related }\end{array}$ & $\begin{array}{l}\text { Directly } \\
\text { fiber } \\
\text { related }\end{array}$ \\
\hline
\end{tabular}

A test method with a high value, according to the initially proposed criterion as seen ion Table 1, is sought. To this end, the criterion is applied to the existing QC tests per the specification as defined by Table 2 in ASTM D7957. The criterion is applied based 
on average performance provided by certified laboratories, known best practices and engineering judgements specific to FRP composites. Accordingly, three primary QC tests are assessed using the criterion and values and compared to the flexural test method (described in this study): i) Moisture absorption, ii) Tensile properties, iii) Fiber mass content, iv) Glass transition temperature, v) degree of cure, and vi) measured area. Figure 1 summarises the QC test methods as assessed per the criterion and are compared to the proposed flexural test (discussed in the next Section). It should be noted that the level of repeatability and reliability resultant from the ASTM QC specification test methods is assumed to be equivalent.

It is worth mentioning, that non-destructive testing (NDT) methods can be effectively used for the QC, evaluation of FRP materials, especially during the manufacturing processes, to increase the reliability of the finished manufactured rebar (Campbell, 2013). Some of the most common methods include visual inspection, liquid penetrant, magnetic article inspection, eddy current testing, $\mathrm{x}$-ray, ultrasonic testing, and thermography amongst some (Raišutis et al., 2011). It should be noted that these test methods are out of the scope of this study and are not included as part of the QC evaluation, the study focuses on destructive testing (DT) QC methods on the manufactured rebar. Nevertheless, a comprehensive QC methodology should include such techniques, especially during the manufacturing process to assure the control of the different stages of production.

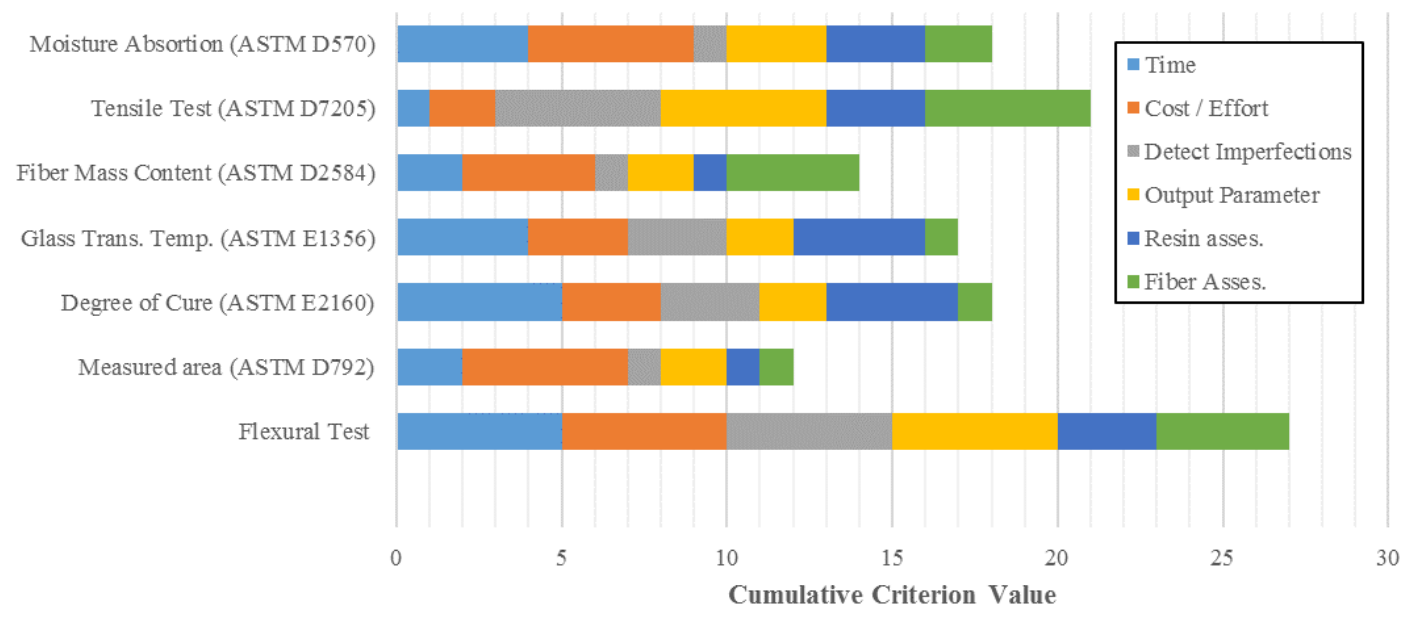

Figure 1. Evaluation of existing and proposed QC tests

According to the proposed criterion, existing QC test methods rank as follows from the most valuable to least valuable: 1) tensile test, 2) fiber mass content, 3) moisture absorption, 4) degree of cure, 5) glass transition temperature, 6) measured area. It is also observed that the only significantly relevant test - in terms of design - is the tensile test. Having only one QC test that can evaluate design values is a reflection of a low reliability QC method, therefore there is a need to increase the reliability and validate the quality of manufactured FRP rebars. Moreover, the limited response time of QC 
testing (blue bar) directly related to design properties and manufacturing process is apparent. This initial criterion shows the need of additional QC tests is essential (Trejo et al, 2005). To this end, flexural tests can provide manufacturers with an additional QC tool to increase the reliability of the manufactured composite rebars, resulting in higher confidence, and quality, and a step closer towards implementing a QC manufacturing certification program. This test is included in the criterion and ranks highest as seen in Error! Reference source not found.

\section{METHODOLOGY}

Eight different FRP rebar manufactures as seen in Figure 1, were selected to conduct flexural tests per ASTM D7264, ASTM D4476, and ASTM D6272. Preliminary tests evaluated different parameters to define a test protocol and configuration based desired failure mode, specimen diameter, set up and repeatability.

Table 2 provides the summary of the findings of this preliminary evaluation.

Table 2. Preliminary evaluation of flexural tests: parameters and conclusions.

\begin{tabular}{|c|c|c|}
\hline Parameter & Description & Conclusion \\
\hline Ratio & $\begin{array}{l}\text { Evaluate effect test } \\
\text { rates: displacement } \\
\text { controlled rates } \\
\text { between } 1.2 \mathrm{~mm} / \mathrm{min} \\
-5 \mathrm{~mm} / \mathrm{min}\end{array}$ & $\begin{array}{l}\text { High variability. Based on ASTM D4476 } \\
\text { and several studies such as (Benmokrane } \text { et } \\
\text { al., 2017b) and (Benmokrane } \text { et al., 2017a) } \\
\text { the optimum rate with least variability and } \\
\text { higher reliability was selected at } 3.8 \\
\mathrm{~mm} / \mathrm{min} \text {. }\end{array}$ \\
\hline $\begin{array}{l}\text { Span-to- } \\
\text { diameter } \\
\text { ratio }\end{array}$ & $\begin{array}{l}\text { Evaluate effect of set- } \\
\text { up according to the } \\
\text { ASTM D6272 } 1: 16 \text {, } \\
1: 20,1: 25,1: 32 \text {, and } \\
1: 40\end{array}$ & $\begin{array}{l}\text { The ratio } 1: 25 \text { was identified as the } \\
\text { minimum to avoid shear failure and the } \\
\text { failure mode happen only due to the bending } \\
\text { moment }\end{array}$ \\
\hline Diameter bar & $\begin{array}{l}\text { Evaluate performance } \\
\text { between different } \\
\text { specimen (rebars) } \\
\text { sizes: } 9.5 \mathrm{~mm}, 12.7 \\
\text { mm and } 25.4 \mathrm{~mm} \text {. }\end{array}$ & $\begin{array}{l}\text { The effect of the diameter is as expected, the } \\
\text { diameter is directly proportional to load } \\
\text { carrying capacity in flexure. }\end{array}$ \\
\hline $\begin{array}{l}\text { Failure mode } \\
\text { classification }\end{array}$ & $\begin{array}{l}\text { Evaluate the mode of } \\
\text { failure, in terms of } \\
\text { sequence of failure } \\
\text { mode progress and } \\
\text { reduce the shear } \\
\text { effects (i.e. increasing }\end{array}$ & $\begin{array}{l}\text { Shorter spans resulted in shear effects } \\
\text { (compression section failure). This effects } \\
\text { of this failure aims to be reduced so that } \\
\text { tensile effects are evaluated. Thus a span-to- } \\
\text { diameter ratio } 1: 25 \text {, based on diameter was } \\
\text { selected reducing the effect of local } \\
\text { buckling of fibers. }\end{array}$ \\
\hline
\end{tabular}




\begin{tabular}{lll}
\hline the span-to-diameter & \\
ratio). & \\
\hline Manufactures & $\begin{array}{l}\text { Evaluate performance } \\
\text { and magnitude of } \\
\text { results between } \\
\text { manufactures: eight } \\
\text { different } \\
\text { manufactures . }\end{array}$ & $\begin{array}{l}\text { A significant inconsistency in the results } \\
\text { between manufactures was observed. This } \\
\text { may be due to manufacturing process, fiber } \\
\text { content and resin type...etc. This is also } \\
\text { observed in tensile properties between } \\
\text { manufactures and thus correlates as } \\
\text { expected to the different behaviour between } \\
\text { manufactures. }\end{array}$ \\
\hline Load Set up & $\begin{array}{l}\text { Evaluate the effect of } \\
\text { different test up: 3- } \\
\text { point, 4-point }\end{array}$ & $\begin{array}{l}\text { The difference between the two set ups was } \\
\text { negligible. 3-point was selected since: i) it } \\
\text { reduces set-up time and can lead to less } \\
\text { setting up inaccuracies (same set up fixtures } \\
\text { as ASTM D4475). ii) According to Mujika } \\
\text { (2006) the span effect due to the rotation of } \\
\text { the supports and span is necessary to take } \\
\text { into account and apply a correction factor, } \\
\text { which smaller in 3-point set up. }\end{array}$ \\
&
\end{tabular}

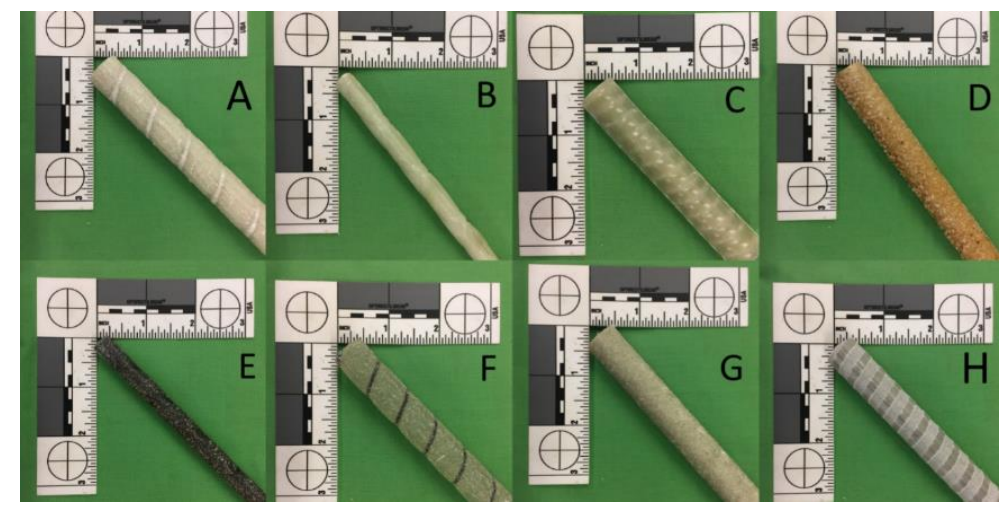

(a)

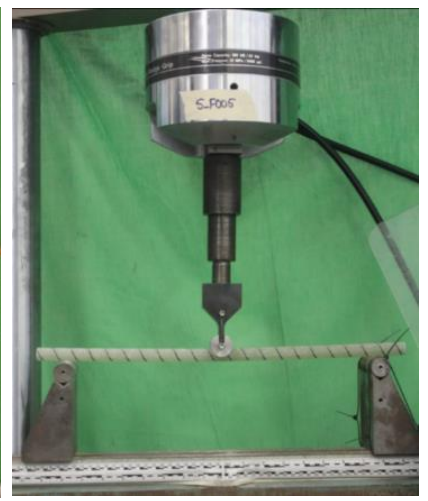

(b)

Figure 2. (a) Selected FRP rebars from 8 different manufactures; (b) Three-point bending test set up

Based on the results from the preliminary evaluation of the flexural tests, a configuration and procedure was defined to conduct a feasibility study to validate the flexural test methodology as a reliable QC technique for FRP rebars as follows.

\subsection{Materials}

Three representative FRP rebar manufactures $(\mathrm{A}, \mathrm{F}$ and $\mathrm{H})$ were selected as well as three different rebar sizes (nominal sizes: $9.5 \mathrm{~mm}, 12.7 \mathrm{~mm}$ and $25.4 \mathrm{~mm}$ ). The rebar selection was made to account for different manufacturing techniques, resins and surface enhancements, the fiber was kept constant: glass. The diameters were 
experimentally measured per the specifications and following ASTM D792, to confirm the setup.

\subsection{Specimen Preparation and Test Procedure}

The three-point bending configuration was selected. All the specimens were cut for a span-to-diameter ratio of 1:25, so as to increase the likelihood of a flexural bending type failure mode, and $10 \%$ of the length was left for the overhang on the supports. The test was conducted with two supports with a diameter of $25.4 \mathrm{~mm}$ and the loading nose with a cylindrical surface in order to avoid excessive indentation or localised failure due to the stress concentration under the loading nose. The testing machine used to conduct the tests was a hydraulic universal test frame in displacement control at the rate $3.8 \mathrm{~mm} . / \mathrm{min}$. The test time was monitored and the displacement was calculated according to the displacement of the machine crosshead. Ten flexural test repetitions were conducted for each bar size and manufacture.

On the other hand, tensile tests were performed according to the ASTM D7205 with a displacement controlled universal test frame at a rate of $2 \mathrm{~mm} / \mathrm{min}$, also in compliance with ASTM E4. The specimens were prepared by adding two steel pipe anchors with expansive grout at in each to end to prevent stress concentration when gripping per ASTM D7205 recommendations. According to each evaluated rebar diameter $(9.5 \mathrm{~mm}$, $12.7 \mathrm{~mm}$ and $25.4 \mathrm{~mm}$ ), the anchor length was $300 \mathrm{~mm}, 380 \mathrm{~mm}$ and $460 \mathrm{~mm}$ and the free (gauge) length between the anchors was at least 40 times the effective bar diameter. An extensometer with a gauge length of $200 \mathrm{~mm}$ was used to measure tensile deformation. For each test the experimental ultimate strength, tensile elastic modulus between 1000 and 3000 micro-strain, and computed tensile ultimate strain were determined. Five tensile test repetitions were conducted for each bar size and manufacture.

\section{RESULTS AND DISCUSSION}

The experimental peak load, deflection, stress, strain and flexural modulus for the tested GFRP bars are reported herein. The average (AVE), standard deviation (SD) and coefficient of variance (COV) for the different mechanical values, for the flexural and tensile tests are provided in

Moreover, Mujika et al. (2006) have been able to compute the tensile and compressive moduli based on the flexural modulus for composite laminates, therefore the value provided by the flexural test as a QC tool add significant value, based on the previously proposed criteria (Figure 1). 


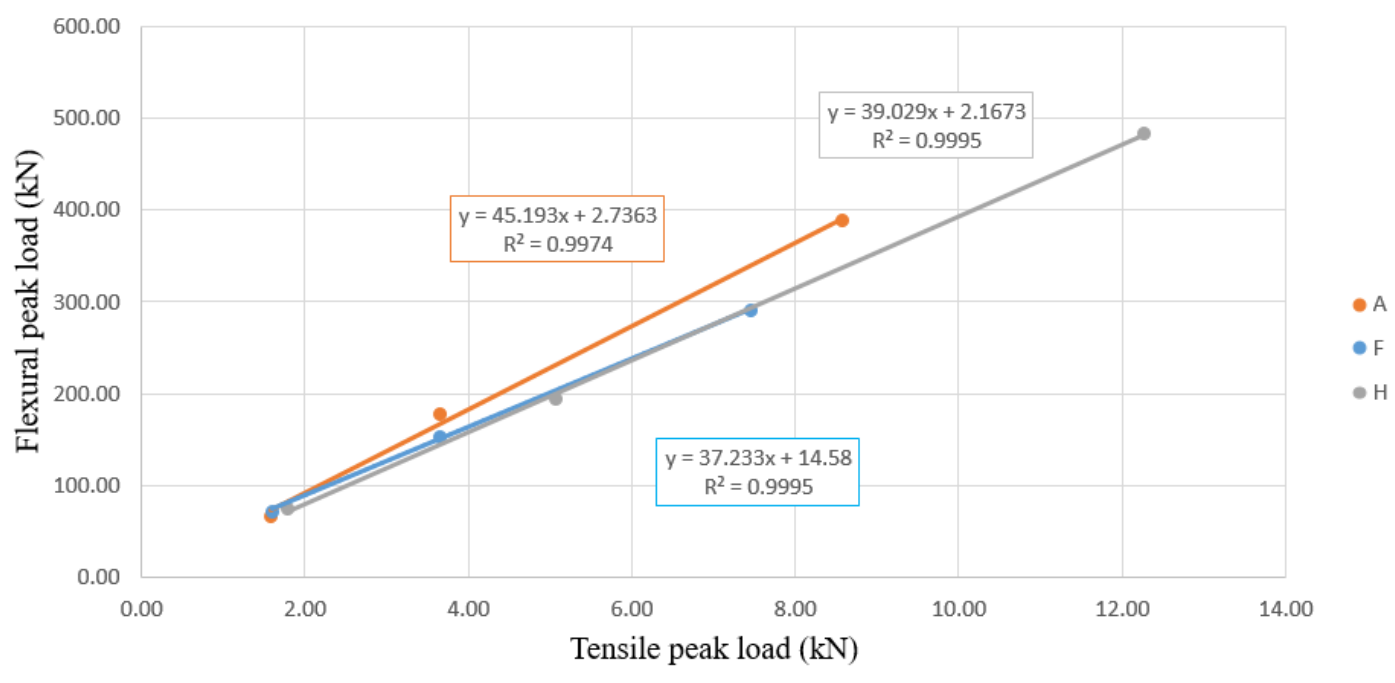

Figure 3. Relationship between average flexural and tensile peak loads 


\begin{tabular}{|c|c|c|c|c|c|c|c|c|c|c|c|c|c|c|c|c|}
\hline \multirow{5}{*}{ 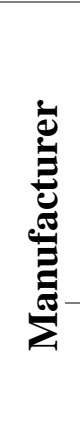 } & \multirow{5}{*}{$\begin{array}{l}\mathbf{S i} \\
\mathbf{z e} \\
\\
\mathrm{m} \\
\mathrm{m}\end{array}$} & \multicolumn{3}{|c|}{ Peak Load } & \multicolumn{3}{|c|}{$\begin{array}{c}\text { Peak } \\
\text { Deflection }\end{array}$} & \multicolumn{3}{|c|}{$\begin{array}{l}\text { Ultimate } \\
\text { Flexural } \\
\text { strength }\end{array}$} & \multicolumn{3}{|c|}{$\begin{array}{l}\text { Ultimate } \\
\text { Flexural } \\
\text { Modulus }\end{array}$} & \multicolumn{3}{|c|}{$\begin{array}{c}\text { Ultimate } \\
\text { Flexural } \\
\text { Strain }\end{array}$} \\
\hline & & $\mathrm{A}$ & $\mathrm{S}$ & $\mathrm{C}$ & $\mathrm{A}$ & $\mathrm{S}$ & $\mathrm{C}$ & $\mathrm{AV}$ & $\mathrm{S}$ & $\mathrm{C}$ & A & $\mathrm{S}$ & $\mathrm{C}$ & A & $\mathrm{S}$ & $\mathrm{C}$ \\
\hline & & $\mathrm{V}$ & $\mathrm{D}$ & $\mathrm{O}$ & $\mathrm{V}$ & $\mathrm{D}$ & $\mathrm{O}$ & $\mathrm{E}$ & $\mathrm{D}$ & $\mathrm{O}$ & V & $\mathrm{D}$ & $\mathrm{O}$ & V & D & $\mathrm{O}$ \\
\hline & & $\mathrm{E}$ & & $\mathrm{V}$ & $\mathrm{E}$ & & $\mathrm{V}$ & & & V & $\mathrm{E}$ & & V & $\mathrm{E}$ & & $\mathrm{V}$ \\
\hline & & $\begin{array}{l}\mathrm{k} \\
\mathrm{N}\end{array}$ & $\begin{array}{l}\mathrm{k} \\
\mathrm{N}\end{array}$ & $\%$ & $\begin{array}{l}\mathrm{m} \\
\mathrm{m}\end{array}$ & $\begin{array}{l}\mathrm{m} \\
\mathrm{m}\end{array}$ & $\%$ & $\begin{array}{c}\mathrm{MP} \\
\mathrm{a}\end{array}$ & $\begin{array}{l}\mathrm{M} \\
\mathrm{Pa}\end{array}$ & $\%$ & $\begin{array}{l}\mathrm{G} \\
\mathrm{Pa}\end{array}$ & $\begin{array}{l}\mathrm{G} \\
\mathrm{P} \\
\mathrm{a}\end{array}$ & $\%$ & $\%$ & $\%$ & $\%$ \\
\hline \multirow{6}{*}{$\mathbf{A}$} & 9. & 1. & & 6. & 22 & 2. & 12 & 110 & 69 & 6. & 52 & 3. & 5. & 2. & 0 & 12 \\
\hline & 5 & 6 & $\dot{1}$ & 3 & .6 & 8 & .2 & 4.6 & .8 & 3 & .0 & 1 & 9 & 3 & 3 & .2 \\
\hline & 1 & 3. & 0 & 5. & 32 & 1. & 4. & 924 & 54 & 5. & 50 & 3. & 6. & 1. & 0 & 4. \\
\hline & $\begin{array}{l}2 . \\
7\end{array}$ & 7 & $\dot{2}$ & 9 & .0 & 3 & 0 & .0 & .8 & 9 & .7 & 2 & 4 & 9 & $\dot{1}$ & 0 \\
\hline & 2 & 8. & 0 & 5. & 49 & 3. & 7. & 847 & 43 & 5 . & 48 & 2. & 5 . & 1. & 0 & 7. \\
\hline & $\begin{array}{l}5 . \\
4\end{array}$ & 6 & $\dot{4}$ & 1 & .9 & 7 & 3 & .1 & .1 & 1 & .5 & 5 & 2 & 9 & $\dot{1}$ & 3 \\
\hline \multirow{6}{*}{$\mathbf{F}$} & 9. & 1. & 0 & 7. & 19 & 1. & 6. & 112 & 80 & 7. & 64 & 3. & 4. & 2. & 0 & 6. \\
\hline & 5 & 6 & $\dot{1}$ & 1 & .6 & 3 & 7 & 4.3 & .2 & 1 & .8 & 0 & 6 & 0 & $\dot{1}$ & 7 \\
\hline & 1 & 3. & 0 & 7. & 39 & 3. & 8. & 921 & 68 & 7. & 40 & 0 . & 1. & 2. & 0 & 8. \\
\hline & $\begin{array}{l}2 . \\
7\end{array}$ & 7 & $\dot{3}$ & 4 & .5 & 2 & 1 & .5 & .6 & 4 & .0 & 6 & 5 & 4 & $\dot{2}$ & 1 \\
\hline & 2 & 7. & 0 & 5. & 56 & 3. & 6. & 735 & 41 & 5. & 36 & 1. & 3. & 2. & 0 & 6. \\
\hline & $\begin{array}{l}5 . \\
4\end{array}$ & 5 & $\dot{4}$ & 7 & .0 & 4 & 2 & .8 & .9 & 7 & .3 & 1 & 1 & 12 & 1 & 2 \\
\hline \multirow{6}{*}{$\mathbf{H}$} & 9. & 1. & 0 & 5. & 24 & 1. & 4. & 125 & 72 & 5. & 58 & 1. & 2. & 2. & 0 & 4. \\
\hline & 5 & 8 & $\dot{1}$ & 8 & .1 & 0 & 3 & 1.9 & .2 & 8 & .5 & 4 & 5 & 4 & $\dot{1}$ & 3 \\
\hline & 1 & 5. & 0 & 4. & 35 & 1. & 4. & 852 & 40 & 4. & 66 & 2. & 3. & 2. & 0 & 4. \\
\hline & $\begin{array}{l}2 . \\
7\end{array}$ & 1 & $\dot{2}$ & 7 & .0 & 7 & 8 & .9 & .2 & 7 & .4 & 0 & 0 & 1 & 1 & 8 \\
\hline & $\begin{array}{l}2 \\
5\end{array}$ & 12 & 0 & 3. & 49 & 2. & 5. & 807 & 28 & 3. & 72 & 1. & 1. & 1. & 0 & 5. \\
\hline & $\begin{array}{l}5 . \\
4\end{array}$ & .3 & $\dot{4}$ & 5 & .4 & 6 & 2 & .6 & .4 & 5 & .2 & 3 & 9 & 9 & $\dot{1}$ & 2 \\
\hline
\end{tabular}

and Table 4, respectively. Ensuring that the flexural test is a i) reliable, ii) repeatable and iii) reproducible method is fundamental to provide a valuable QC test.

Reliability relates the magnitude of the measurement error in observed measurements to the inherent variability in the 'error-free', 'true', or underlying level of the quantity between test repetitions. These measures of variability can be expressed statistically as the standard deviation (SD). For the set of tests conducted the computed SD is within an acceptable range, where also the coefficients of variance magnitude is acceptable, 
overall being less than $8.1 \%$ in all parameters, resulting in a high reliability for an assumed normal distribution.

Repeatability of measurements refers to the variation in repeat measurements made on the same manufactured rebar size (i.e. from the same production lot) identical conditions (i.e. measurements are made by the same instrument, protocol, technician and time period - which is the case). Variability in measurements made under these conditions can then be ascribed only to errors due to the measurement process itself. Given that the test equipment (load, deflection and rate) was calibrate in compliance with acceptable standards reducing measurement process errors, the test methodology reproduced successfully mechanical parameters, as seen for the set of test results per bar size.

Reproducibility refers to the variation in measurements made on a subject under changing conditions. The changing conditions may be due to different measurement methods or instruments implemented, different technicians, or measurements being made over a period of time, within which the 'error-free' level of the variable could undergo non-negligible change. Although this was not evaluated in this study, interlaboratory testing underway will provide experimental evidence to assess the reproducibility of the test protocol.

In addition, the relationship between the peak loads of the flexural and tensile tests was established for the tests conducted, as seen in Figure 3. According to this, the correlation between the ultimate peak flexural load and ultimate tensile load carrying capacity is linear, with an R-squared value of 0.99 for all manufactures. This statistical value explains how good is the model when compared to the baseline model. Determining such a relationship, which can be seen from the results can vary between manufacturers - especially between $\mathrm{A}$ and $\mathrm{F} / \mathrm{H}$, can be included as part of the specifications of the overall QC methodology. This correlation can be used as a tool to determine variance from expected performance for a manufacturing lot by correlating flexural and tensile tests, while tracking overall consistency and quality of the manufactured rebar at different points in times. Similar relationships can be established for other mechanical parameters such as strain and modulus. Moreover, such correlations can be used to predict tensile properties, anticipating QC tests. Testing of further rebar sizes is needed to establish if the correlation has a limit based on the rebar size.

Moreover, Mujika et al. (2006) have been able to compute the tensile and compressive moduli based on the flexural modulus for composite laminates, therefore the value provided by the flexural test as a QC tool add significant value, based on the previously proposed criteria (Figure 1). 


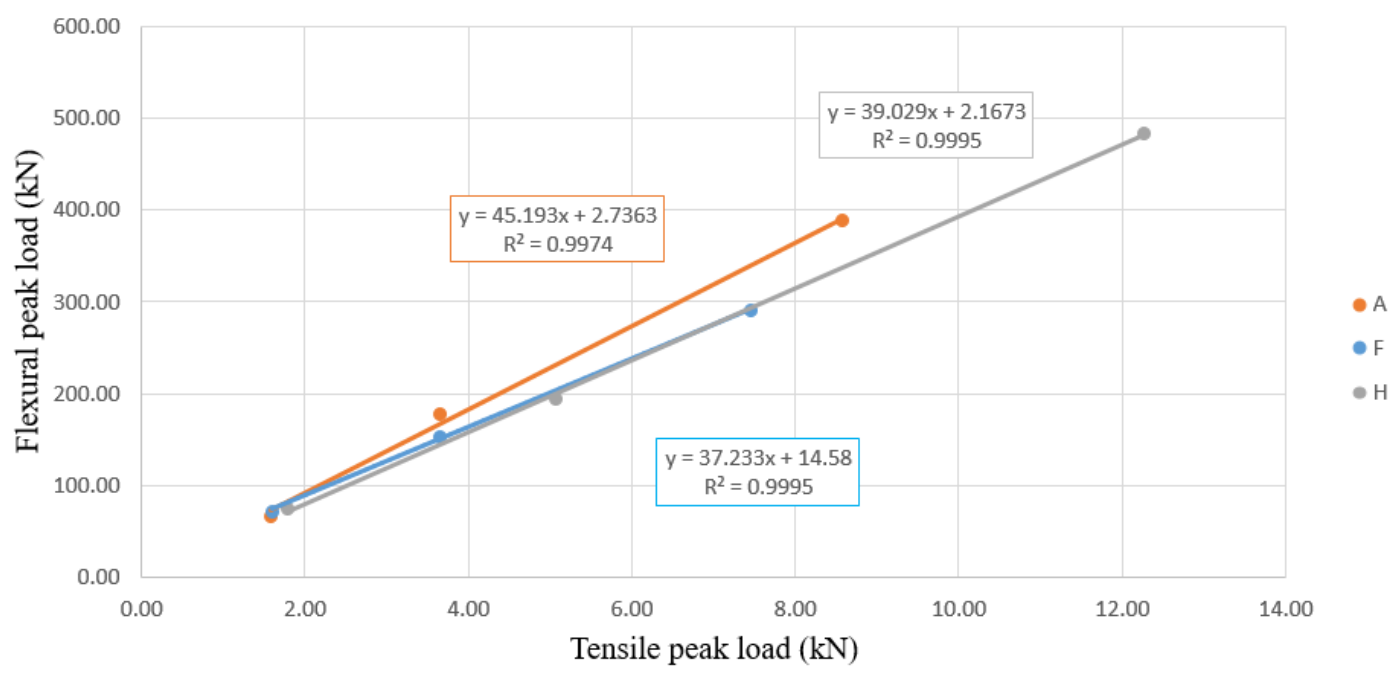

Figure 3. Relationship between average flexural and tensile peak loads 
Table 3. Flexural test average results

\begin{tabular}{|c|c|c|c|c|c|c|c|c|c|c|c|c|c|c|c|c|}
\hline \multirow{3}{*}{ 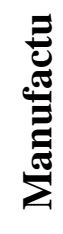 } & \multirow[t]{2}{*}{ Size } & \multicolumn{3}{|c|}{ Peak Load } & \multicolumn{3}{|c|}{ Peak Deflection } & \multicolumn{3}{|c|}{$\begin{array}{c}\text { Ultimate Flexural } \\
\text { strength }\end{array}$} & \multicolumn{3}{|c|}{$\begin{array}{c}\text { Ultimate Flexural } \\
\text { Modulus }\end{array}$} & \multicolumn{3}{|c|}{$\begin{array}{c}\text { Ultimate Flexural } \\
\text { Strain }\end{array}$} \\
\hline & & AVE & $\mathrm{SD}$ & $\mathrm{COV}$ & AVE & $\mathrm{SD}$ & $\mathrm{COV}$ & AVE & SD & $\mathrm{COV}$ & AVE & $\mathrm{SD}$ & $\mathrm{COV}$ & AVE & $\mathrm{SD}$ & $\mathrm{COV}$ \\
\hline & $\mathrm{mm}$ & $\mathrm{kN}$ & $\mathrm{kN}$ & $\%$ & $\mathrm{~mm}$ & $\mathrm{~mm}$ & $\%$ & $\mathrm{MPa}$ & $\mathrm{MPa}$ & $\%$ & $\mathrm{GPa}$ & $\mathrm{GPa}$ & $\%$ & $\%$ & $\%$ & $\%$ \\
\hline \multirow{3}{*}{$\mathbf{A}$} & 9.5 & 1.6 & 0.1 & 6.3 & 22.6 & 2.8 & 12.2 & 1104.6 & 69.8 & 6.3 & 52.0 & 3.1 & 5.9 & 2.3 & 0.3 & 12.2 \\
\hline & 12.7 & 3.7 & 0.2 & 5.9 & 32.0 & 1.3 & 4.0 & 924.0 & 54.8 & 5.9 & 50.7 & 3.2 & 6.4 & 1.9 & 0.1 & 4.0 \\
\hline & 25.4 & 8.6 & 0.4 & 5.1 & 49.9 & 3.7 & 7.3 & 847.1 & 43.1 & 5.1 & 48.5 & 2.5 & 5.2 & 1.9 & 0.1 & 7.3 \\
\hline \multirow{3}{*}{$\mathbf{F}$} & 9.5 & 1.6 & 0.1 & 7.1 & 19.6 & 1.3 & 6.7 & 1124.3 & 80.2 & 7.1 & 64.8 & 3.0 & 4.6 & 2.0 & 0.1 & 6.7 \\
\hline & 12.7 & 3.7 & 0.3 & 7.4 & 39.5 & 3.2 & 8.1 & 921.5 & 68.6 & 7.4 & 40.0 & 0.6 & 1.5 & 2.4 & 0.2 & 8.1 \\
\hline & 25.4 & 7.5 & 0.4 & 5.7 & 56.0 & 3.4 & 6.2 & 735.8 & 41.9 & 5.7 & 36.3 & 1.1 & 3.1 & 2.12 & 0.1 & 6.2 \\
\hline \multirow{3}{*}{$\mathbf{H}$} & 9.5 & 1.8 & 0.1 & 5.8 & 24.1 & 1.0 & 4.3 & 1251.9 & 72.2 & 5.8 & 58.5 & 1.4 & 2.5 & 2.4 & 0.1 & 4.3 \\
\hline & 12.7 & 5.1 & 0.2 & 4.7 & 35.0 & 1.7 & 4.8 & 852.9 & 40.2 & 4.7 & 66.4 & 2.0 & 3.0 & 2.1 & 0.1 & 4.8 \\
\hline & 25.4 & 12.3 & 0.4 & 3.5 & 49.4 & 2.6 & 5.2 & 807.6 & 28.4 & 3.5 & 72.2 & 1.3 & 1.9 & 1.9 & 0.1 & 5.2 \\
\hline
\end{tabular}


Table 4. Tensile test average results

\begin{tabular}{|c|c|c|c|c|c|c|c|c|c|c|c|c|c|}
\hline \multirow{3}{*}{ 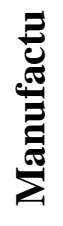 } & \multirow[t]{2}{*}{ Size } & \multicolumn{3}{|c|}{ Peak Load } & \multicolumn{3}{|c|}{ Ultimate Tensile strength } & \multicolumn{3}{|c|}{ Ultimate Tensile Modulus } & \multicolumn{3}{|c|}{ Ultimate Tensile Strain } \\
\hline & & AVE & SD & $\mathrm{COV}$ & AVE & $\mathrm{SD}$ & $\mathrm{COV}$ & AVE & $\mathrm{SD}$ & $\mathrm{COV}$ & AVE & SD & $\mathrm{COV}$ \\
\hline & $\mathrm{mm}$ & $\mathrm{kN}$ & $\mathrm{kN}$ & $\%$ & $\mathrm{MPa}$ & $\mathrm{MPa}$ & $\%$ & $\mathrm{GPa}$ & $\mathrm{GPa}$ & $\%$ & $\%$ & $\%$ & $\%$ \\
\hline \multirow{3}{*}{$\mathbf{A}$} & 9.5 & 67.3 & 3.4 & 5.1 & 838.6 & 46.3 & 5.5 & 45.3 & 2.3 & 5.1 & 1.9 & 0.1 & 3.4 \\
\hline & 12.7 & 177.4 & 7.8 & 4.4 & 826.3 & 36.3 & 4.4 & 49.6 & 2.3 & 4.7 & 1.7 & 0.1 & 4.7 \\
\hline & 25.4 & 387.9 & 23.1 & 5.9 & 736.5 & 43.8 & 5.9 & 50.5 & 2.2 & 4.3 & 1.5 & 0.1 & 3.9 \\
\hline \multirow{3}{*}{$\mathbf{F}$} & 9.5 & 72.4 & 1.3 & 1.8 & 872.4 & 15.4 & 1.8 & 47.5 & 1.7 & 3.5 & 1.8 & 0.1 & 4.9 \\
\hline & 12.7 & 153.3 & 4.9 & 3.2 & 762.9 & 20.2 & 2.7 & 46.3 & 2.4 & 5.2 & 1.6 & 0 & 2.9 \\
\hline & 25.4 & 291.2 & 12.4 & 4.3 & 614.6 & 22.7 & 3.7 & 50.4 & 5.2 & 10.3 & 1.2 & 0.1 & 8.4 \\
\hline \multirow{3}{*}{$\mathbf{H}$} & 9.5 & 75.3 & 1.4 & 1.8 & 1034.7 & 10.9 & 1.0 & 50.2 & 1.4 & 2.8 & 2.1 & 0.1 & 2.5 \\
\hline & 12.7 & 194.7 & 8.9 & 4.6 & 1098.4 & 35.1 & 3.2 & 59.0 & 2.3 & 3.9 & 1.9 & 0.1 & 6.6 \\
\hline & 25.4 & 482.9 & 25.9 & 5.4 & 917.1 & 94.6 & 10.3 & 61.7 & 2.8 & 4.5 & 1.6 & 0.1 & 8.5 \\
\hline
\end{tabular}




\section{CONCLUSION}

This study presents an initial quality control (QC) assessment criterion, which is applied to ASTM D7959 Table 2 (QC specifications). The initial criterion is composed of five considerations and a value between 1 and 5 was then defined. Based on the criterion, although the tensile test ranks highest, the QC specification reveals shortcomings in terms of reliability and response time. To this end, a flexural test was proposed to provide additional assurance and add value to the QC of manufactured FRP rebars validating physio-mechanical properties which can be directly related to design properties.

Following a preliminary evaluation of parameters to define a test protocol and configuration based desired failure mode, specimen diameter, set up and repeatability; a three-point bending and span-to-diameter ratio of 1:25 configuration was successfully validated with three different FRP rebar manufactures and three different bar diameters (nominally, $9.5 \mathrm{~mm}, 12.7 \mathrm{~mm}$ and $25.4 \mathrm{~mm}$ ) per manufacturer. The test revealed to provide simplistic methodology, cost effectiveness and fast response time. Moreover, a linear correlation between the flexural and tensile strength properties was established, and additional mechanical properties such as tensile and compressive E-Moduli may be possible adjusting some analytical approaches.

This represents an initial step towards providing a reliable QC methodology for composite rebar manufactures, acknowledging that other tests need to be included during and after the manufacturing process (e.g. NDT) as part of a holistic QC program.

\section{REFERENCES}

ASTM D4475 (2016), Test Method for Apparent Horizontal Shear Strength of Pultruded Reinforced Plastic Rods By the Short-Beam Method, ASTM International, West Conshohocken, PA.

ASTM D4476 (2014), Test Method for Flexural Properties of Fiber Reinforced

Pultruded Plastic Rods, ASTM International, West Conshohocken, PA.

ASTM D6272 (2017), Test Method for Flexural Properties of Unreinforced and

Reinforced Plastics and Electrical Insulating Materials by Four-Point Bending, ASTM International, West Conshohocken, PA.

ASTM D7264 (2015), Test Method for Flexural Properties of Polymer Matrix

Composite Materials, ASTM International, West Conshohocken, PA.

ASTM D792 (2013), Test Methods for Density and Specific Gravity (Relative

Density) of Plastics by Displacement, ASTM International, West Conshohocken, PA.

ASTM D7957 (2017), Standard Specification for Solid Round Glass Fiber

Reinforced Polymer Bars for Concrete Reinforcement, ASTM International, West Conshohocken, PA. 
Benmokrane, B., Ali, A.H., Mohamed, H.M., ElSafty, A. and Manalo, A. (2017a), "Laboratory assessment and durability performance of vinyl-ester, polyester, and epoxy glass-FRP bars for concrete structures”, Composites Part B: Engineering, Vol. 114, pp. 163-174.

Benmokrane, B., Manalo, A., Bouhet, J.-C., Mohamed, K. and Robert, M. (2017b), "Effects of Diameter on the Durability of Glass Fiber-Reinforced Polymer Bars Conditioned in Alkaline Solution", Journal of Composites for Construction, Vol. 21 No. 5, p. 4017040.

Campbell, F.C. (2013), Inspection of metals: Understanding the basics / edited by F.C. Campbell, ASM International, Materials Park, Ohio.

Corli Leonard (2011), "Quality Assurance in the Aerospace Industry: Implementation of AS 9100 Quality Management Standard at an SME", University of Stellenbosch, March 2011.

Trejo, D Aguiñiga F, James RW, and Keating PB (2005), "Preliminary quality control/quality assurance standards (criteria) for inspection and testing of FRP bars".

Mujika, F. (2006), "On the difference between flexural moduli obtained by threepoint and four-point bending tests", Polymer Testing, Vol. 25 No. 2, pp. 214-220.

Mujika, F., Carbajal, N., Arrese, A. and Mondragon, I. (2006), "Determination of tensile and compressive moduli by flexural tests", Polymer Testing, Vol. 25 No. 6, pp. 766-771.

Nanni, A., Luca, A. de and Jawaheri Zadeh, H. (2014), Reinforced concrete with FRP bars: Mechanics and design, CRC Press, Boca Raton.

Raišutis, R., Kažys, R., Žukauskas, E. and Mažeika, L. (2011), "Ultrasonic aircoupled testing of square-shape CFRP composite rods by means of guided waves", NDT \& E International, Vol. 44 No. 7, pp. 645-654.

Whitney, J.M. and Knight, M. (1980), “The relationship between tensile strength and flexure strength in fiber-reinforced composites", Experimental Mechanics, Vol. 20 No. 6, pp. 211-216.

Wind energy generation systems, Wind turbine blades No. IEC 61400, IEC International Standards. 